\title{
Chemical structure of cichorinotoxin, a cyclic lipodepsipeptide that is produced by Pseudomonas cichorii and causes varnish spots on lettuce
}

\author{
Hidekazu Komatsu ${ }^{1}$, Takashi Shirakawa ${ }^{2}$, Takeo Uchiyama ${ }^{1}$ and Tsutomu Hoshino*1,§
}

\author{
Full Research Paper \\ Address: \\ ${ }^{1}$ Department of Applied Biological Chemistry, Faculty of Agriculture \\ and Graduate School of Science and Technology, Niigata University, \\ Ikarashi 2-8050, Nishi-ku, Niigata 950-2181, Japan and 2Department \\ of Planning and General Administration, Institute of Vegetable and \\ Floriculture Science, National Agriculture and Food Research \\ Organization, 3-1-1 Kannondai, Tsukuba, Ibaraki 305-8519, Japan \\ Email: \\ Tsutomu Hoshino* - hoshitsu@agr.niigata-u.ac.jp \\ * Corresponding author \\ $\S$ Fax: +81-25-262-6854 \\ Keywords: \\ cichorinotoxin; lipodepsipeptide; necrotic lesion of lettuce; phytotoxin; \\ Pseudomonas cichorii
}

\author{
Beilstein J. Org. Chem. 2019, 15, 299-309. \\ doi:10.3762/bjoc. 15.27
}

Received: 28 September 2018

Accepted: 22 January 2019

Published: 01 February 2019

Associate Editor: N. Sewald

(c) 2019 Komatsu et al.; licensee Beilstein-Institut.

License and terms: see end of document.

\begin{abstract}
Pseudomonas cichorii, which causes varnish spots on lettuce and seriously damages lettuce production during the summer season in the highland areas of Japan (e.g., Nagano and Iwate prefectures) was isolated. The structure of a toxin produced by this organism was analyzed based on the detailed evaluation of its $2 \mathrm{D}$ NMR and FABMS spectra, and this compound has not been reported previously. We propose the name cichorinotoxin for this toxin. In conjunction with the D or L configurations of each amino acid, which were determined by Marfey's method, we propose the structure of cichorinotoxin to be as follows: 3-hydroxydecanoyl-(Z)-dhThr ${ }^{1}-$

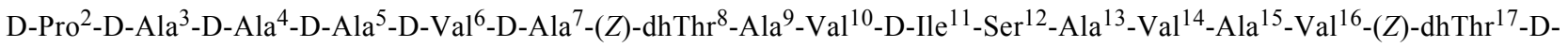

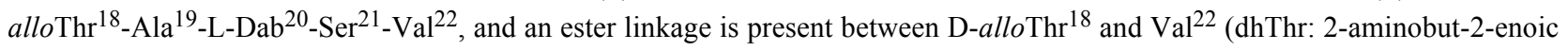
acid; Dab: 2,4-diaminobutanoic acid). Thus, the toxin is a lipodepsipeptide with 22 amino acids. The mono- and tetraacetate derivatives and two alkaline hydrolysates, compounds $\mathbf{A}$ and $\mathbf{B}$, were prepared. We discuss here the structure-activity relationships between the derivatives and their necrotic activities toward lettuce.
\end{abstract}

\section{Introduction}

Pseudomonas cichorii causes varnish spots on lettuce. Varnish spots, also called midrib rot or bacterial rot [1-4], are dark brown and can induce necrotic lesions [1-7]. P. cichorii, isolated by us, infects a wide range of host plants, including monocot and dicot species (e.g., Asteraceae, Solanaceae, Apiaceae, and Liliaceae; 54 species in 17 families) [5], but necrotic lesions most commonly occur in lettuce plants and seriously hurt lettuce production in the highland areas of Japan (e.g., Nagano 
and Iwate prefectures) in the summer season [5]. Effective ways of inhibiting the infection are of great interest, but the infection mechanism remains unknown. We isolated a phytotoxin from the bacterial bodies of $P$. cichorii isolate YM8705 to clarify its mechanism of action. An injection of $750 \mathrm{pg}$ of the isolated toxin caused necrotic lesions on lettuce midrib [5]. Furthermore, this toxin was confirmed to have an elicitor-like effect on the production of the phytoalexin lettucenin A [6-8]. As described below, the toxin was determined to be a cyclic lipodepsipeptide composed of a 3-hydroxydecanoic acid moiety and 22 amino acid residues. Two types of cyclic lipodepsipeptide phytotoxins are well known: relatively lower molecular weight compounds composed of 9 amino acids, such as those found in syringostatin [9], syringomycin [10,11] and syringotoxin [12], and higher molecular weight compounds consisting of 22 or 25 amino acids, which have been found in syringopeptins [13].

Herein, we report the structural determination of the toxin produced by $P$. cichorii YM8705, which was determined mainly from detailed analyses of its $2 \mathrm{D}$ NMR spectra. Although the structure is similar to that of syringopeptin $22 \mathrm{~A}$, composed of 22 amino acids, it is not identical, and this new phytotoxic compound has not been reported previously; we propose the name cichorinotoxin for this compound. Very recently, Huang et al. reported new phytotoxins, named cichopeptin A and B, from P. cichorii SF1-54 [14], which cause midrib rot disease in lettuce much like cichorinotoxin. However, cichorinotoxin is structurally distinct from the cichopeptins. The structural differences are as follows: four of the amino acid residues are different, and the lipophilic fatty acid also differs between the two toxins. Moreover, one of 22 amino acids was not definitively identified. Thus, cichopeptins A and B are different compounds compared to the cichorinotoxin isolated by us. The structure of cichopeptin proposed by Huang et al. was determined mainly by MS/MS spectral analyses, and the stereochemistry (D, L) of each of the amino acids was not determined. Herein, we present the almost complete assignments of all the ${ }^{1} \mathrm{H}$ and ${ }^{13} \mathrm{C}$ NMR signals of cichorinotoxin, and we determined the stereochemistry of 12 out of the 22 amino acids. In addition, we prepared chemically modified derivatives of cichorinotoxin and evaluated the abilities of some derivatives to cause lettuce rot, in order to provide insight into which structural units have a crucial role for causing the phytotoxic activity.

\section{Results and Discussion Composition of cichorinotoxin: 3-hydroxydecanoic acid and 22 amino acids}

The culture conditions of $P$. cichorii YM8705 and the isolation procedure are described in the Experimental section. This toxin was isolated as a white solid. Its IR spectrum $(\mathrm{KBr}$ tablet,
Supporting Information File 1, Figure S1) showed strong and broad absorption bands at $1535 \mathrm{~cm}^{-1}$ and $1660 \mathrm{~cm}^{-1}$, indicating that cichorinotoxin has amide groups and that it is a peptide. In addition, a band at $1740 \mathrm{~cm}^{-1}$ (medium) was also observed, suggesting that an ester bond is present. This toxin was subjected to Edman degradation, but this technique provided no information about the composition of the amino acids, suggesting that the amino group at the N-terminus is modified or blocked. However, this toxin was positive for ninhydrin; thus, a basic amino functional group is likely present in cichorinotoxin. FABMS (positive mode; matrix: $m$-nitrobenzyl alcohol, NBA) showed signals at $m / z 2069[\mathrm{M}+\mathrm{H}]^{+}$and $m / z 2070$ (isotope peak), and signals at $m / z 2067[\mathrm{M}-\mathrm{H}]^{+}$and $\mathrm{m} / \mathrm{z} 2068$ (isotope peak) were observed in the negative mode (Supporting Information File 1, Figure S2). This finding demonstrates that the molecular ion of cichorinotoxin $\left(\mathrm{M}^{+}\right)$is $\mathrm{m} / \mathrm{z} 2068$. To clarify the amino acid composition, cichorinotoxin was hydrolyzed in $6 \mathrm{~N} \mathrm{HCl}$ at $110^{\circ} \mathrm{C}$ for $5 \mathrm{~h}, 10 \mathrm{~h}$ and $22 \mathrm{~h}$, and analysis of the amino acids in the hydrolytic residues showed that Thr, Ser, Pro, Ala and Val were present in the structure of this toxin. To determine the stereochemistry (either D or L) of each amino acid, the hydrolytic residues were reacted with Marfey's reagent (1-fluoro-2,4-dinitrophenyl-5-L-alaninamide, FDAA) [15] to generate diastereomers. The diastereomers were then separated by HPLC with a $\mathrm{C}_{18}$ column using a solvent system composed of $\mathrm{CH}_{3} \mathrm{CN}$ and triethylamine phosphate ( $\mathrm{pH}$ 3.0, see Figures S5B-S5E, Supporting Information File 1). Marfey's method revealed the presence of 2,4diaminobutanoic acid (Dab) and Ile in the toxin (Figures S5B and S5D). Four diastereomers are present in both Thr and Ile (structures, see Figure S5A, Supporting Information File 1): L-allo-type; L-threo-type; D-threo-type; and D-allo-type. The four diastereomers (FDAA derivatives) of Thr were well separated by HPLC (Supporting Information File 1, Figure S5C). In contrast, in the case of the Ile derivatives, separations between the L-allo- and L-threo-types and between the D-allo- and D-threo-types were unsuccessful, but separations between the L-allo- and D-allo-Ile and between the L-threo- and D-threo-Ile were achieved (Supporting Information File 1, Figure S5E). Consequently, the HPLC analyses demonstrated that the Thr residue in the toxin was the $\mathrm{D}$-allo-form with $(2 R, 3 R)$-stereochemistry, and the Ile residue was either the D-allo-derivative, with $(2 R, 3 S)$-stereochemistry, or the D-threoform, with $(2 R, 3 R)$-stereochemistry. Table 1 summarizes the composition and the stereochemistry of each amino acid. As described below, NMR analysis of cichorinotoxin confirmed that three units of dehydrothreonine (dhThr: 2 -aminobut-2-enoic acid) were present in the toxin, and the $Z$-geometry of the double bond was determined by NOESY analysis (see Figure 6 and Supporting Information File 1, Figure S10F). 
Table 1: The proportion of each enantiomer of each amino acid, which were determined by an amino acid analyzer and by the peak areas of the D- and L-amino acids as estimated by Marfey's method.

\begin{tabular}{cccccccc} 
& Ala & Val & Pro & Ser & D-alloThr & Dab $^{\mathrm{b}}$ & $\mathrm{Il}^{\mathrm{c}}$ \\
\hline D & 7.65 & 4.33 & 1.49 & 0.68 & 1.0 & - & 0.91 \\
L & 1.21 & 1.42 & - & 0.82 & - & 0.92 & - \\
\hline
\end{tabular}

The composition ratios of each amino acid presented here were in good agreement with those of the overall structure of cichorinotoxin shown in Figure 6. ${ }^{\mathrm{a} D} \mathrm{D}$-alloThr indicates $(2 R, 3 R)$-stereochemistry. ${ }^{b} \mathrm{Dab}: 2,4$-diaminobutanoic acid. ${ }^{\mathrm{C}}$ The lle residue is either the $\mathrm{D}$-allo- or the D-threo-type and not the L-allo- or L-threo-type.

Analyses of the fragment ions in the FABMS spectrum of cichorinotoxin (Figure 1) showed the presence of the following peptide segment: Pro-Ala-Ala-Ala-Val-Ala-dhThr-Ala-Val (Figure 2). As described below, this toxin has a 3-hydroxydecanoic acid moiety as a fatty acid. Furthermore, the amino group at the $\mathrm{N}$-terminus is modified or blocked, as mentioned above. Observation of a fragment ion of $\mathrm{m} / \mathrm{z} 254$ suggests that the 3-hydroxydecanoyl dehydrothreonine moiety $(\mathrm{m} / z 254)$ is linked to the Pro residue (Figure 2). This segment was further confirmed by detailed NMR analyses (Figure 3 ). To confirm the presence of this fatty acid moiety, cichorinotoxin $(2.0 \mathrm{mg})$ was hydrolyzed at $120^{\circ} \mathrm{C}$ for $90 \mathrm{~min}$ with $1.0 \mathrm{~mL}$ of $6 \mathrm{~N}$ aqueous $\mathrm{HCl}$. EtOAc $(1.5 \mathrm{~mL})$ was added to the hydrolysate, and then the fatty acid was extracted. The extract was dried over anhydrous $\mathrm{MgSO}_{4}$ and concentrated in vacuo. A mixture $(1.0 \mathrm{~mL})$ of trimethylchlorosilane and $\mathrm{N}, \mathrm{O}$-bis(trimethylsilyl)acetamide (10:1) was added to the residue, the solution was heated at
$80{ }^{\circ} \mathrm{C}$ for $24 \mathrm{~h}$. The reaction mixture was then analyzed by GC-MS, which showed $m / z 332$ as the parent ion $\left[\mathrm{M}^{+}\right]$, demonstrating that two TMS molecules were attached (Supporting Information File 1, Figure S3A). Commercially available $( \pm$ )-3-hydroxydecanoic acid was also derivatized with the above mentioned TMS reagent (Supporting Information File 1, Figure $\mathrm{S} 3 \mathrm{~B})$. The two products showed the same GC retention time and fragment ions in the MS, verifying that the fatty acid in cichorinotoxin is 3-hydroxydecanoic acid. As described above, a basic amino acid (positive in the ninhydrin test) is present in cichorinotoxin. To confirm the presence of a free amino group, cichorinotoxin $(6.0 \mathrm{mg})$ was acetylated for $6 \mathrm{~h}$ at room temperature with $\mathrm{Ac}_{2} \mathrm{O}(1.5 \mathrm{~mL})$ in a mixed solvent $(5 \mathrm{~mL})$ composed of $\mathrm{CH}_{3} \mathrm{CN} / \mathrm{pH} 9.7 \mathrm{Na}_{2} \mathrm{CO}_{3} / \mathrm{NaHCO}_{3}$ buffer solution (1:1). The FABMS spectrum (positive mode, NBA matrix, Supporting Information File 1, Figure S4A) showed a signal at $m / z 2111$ [M $+\mathrm{H}]^{+}$, indicating that the monoacetate was obtained; thus, the number of basic amino acids was limited to one. As shown in Table 1, Dab is the only basic amino acid present in the molecule. A prominent peak at $m / z 2133[\mathrm{M}+\mathrm{Na}: 2068+42+23]^{+}$ was observed in addition to the signal at $m / z 2111[\mathrm{M}+\mathrm{H}]^{+}$. In contrast, the reaction with $\mathrm{Ac}_{2} \mathrm{O} / \mathrm{Py}$ showed a parent ion at $\mathrm{m} / \mathrm{z}$ 2259 in the FABMS spectrum ( $m$-NBA matrix, Supporting Information File 1, Figure S4B), which suggested that the tetraacetate was generated $m / z[2068+42 \times 4+23=2259]$, but the molecular ion of the tetraacetate peak $\left(\mathrm{m} / z 2237[\mathrm{M}+\mathrm{H}]^{+}\right)$ did not appear in the FABMS spectrum (Supporting Information File 1, Figure S4B). Consequently, these MS data of the mono- and tetraacetates, which were obtained under controlled

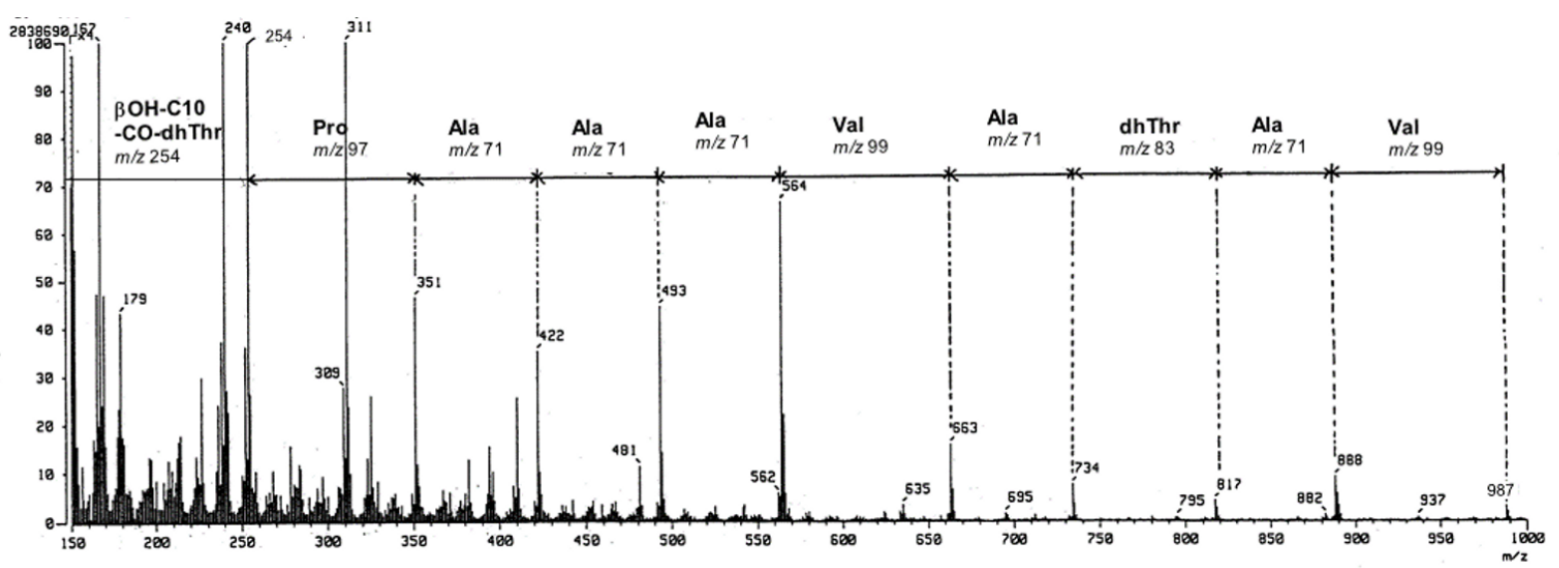

Figure 1: FABMS spectrum (positive mode, NBA matrix) of cichorinotoxin over the mass range of $m / z$ 150-1000.

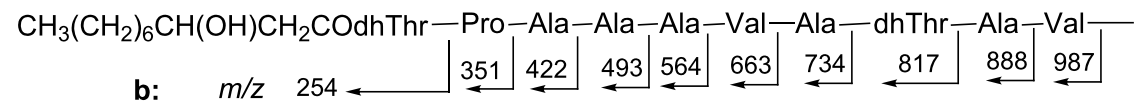

Figure 2: The segment identified based on the FABMS spectrum (peptide fragment $\mathbf{b}$ ions). 


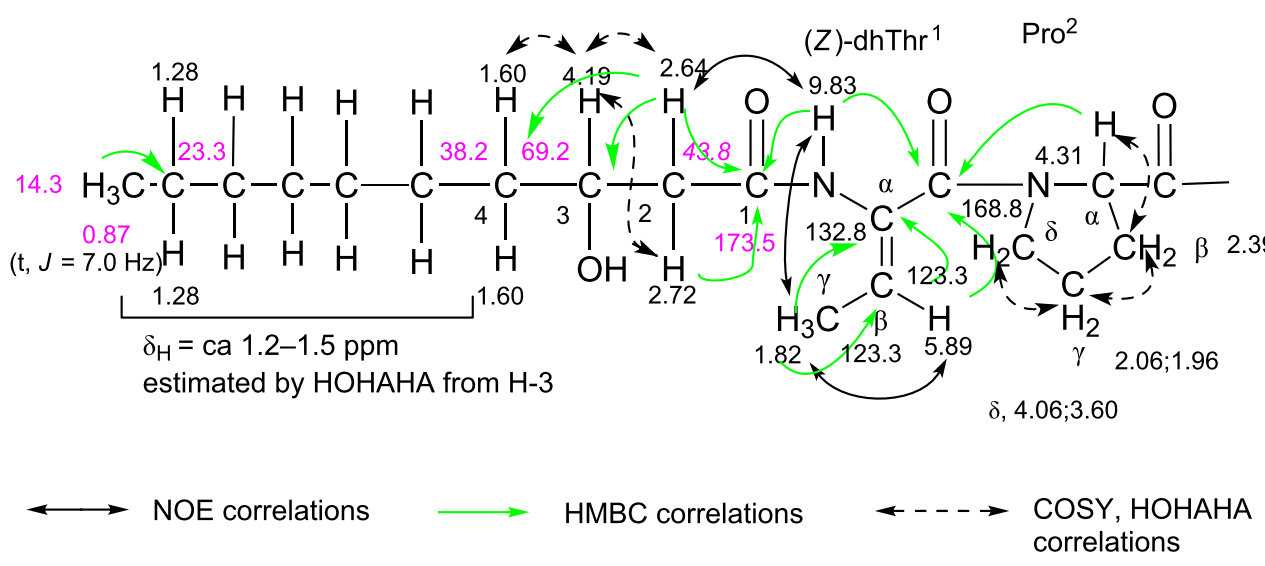

Figure 3: NMR analyses of the segment consisting of 3-hydroxydecanoyl-dehydrothreonin-proline $\left(600 \mathrm{MHz}\right.$, acetone- $\left.d_{6}\right)$. DhThr ${ }^{1}$ and $\mathrm{Pro}^{2}$ indicate that the first and second amino acids in the peptide backbone are dhThr and Pro, respectively.

reaction conditions, clearly indicated that one amino group (Dab) and three $\mathrm{OH}$ groups are present in the toxin. As shown in Table 1, cichorinotoxin has three $\mathrm{OH}$ groups in its structure due to the presence of two serine residues and one threonine residue. In addition, one 3-hydroxyfatty acid is present, as described above (Figure 2). Thus, there are four $\mathrm{OH}$ groups in cichorinotoxin. As mentioned below, the four acetate moieties were determined to be at Dab, the two serine residues and the $\beta$-hydroxyfatty acid based on NMR analyses. Thus, the $\mathrm{OH}$ group on the Thr residue is blocked through an ester linkage (IR, $\left.1740 \mathrm{~cm}^{-1}\right)$.

\section{NMR analyses to determine the overall structure of the monoacetate}

The ${ }^{1} \mathrm{H}$ NMR spectrum of cichorinotoxin (not the acetate derivative) in DMSO- $d_{6}(600 \mathrm{MHz})$ was not sufficiently resolved to elucidate the structure (Supporting Information File 1, Figure S6). However, the ${ }^{1} \mathrm{H}$ NMR signals of the monoacetate were well separated $\left(600 \mathrm{MHz}\right.$, acetone- $d_{6}$, Supporting Information File 1, Figure S7). Therefore, the 1D and 2D NMR spectra of the monoacetate were analyzed to determine the overall structure. The ${ }^{1} \mathrm{H},{ }^{1} \mathrm{H}$ COSY, TOCSY, NOESY, HMQC and HMBC spectra are shown in Supporting Information File 1, Figures
S8-S12. The side chain of each amino acid (type of amino acid) was mainly determined from the ${ }^{1} \mathrm{H},{ }^{1} \mathrm{H}$ COSY and TOCSY spectra. The NOESY spectrum provided important information on the backbone of the amino acid sequence, as depicted in Figure 4. The presence of a dhThr moiety in cichorinotoxin was confirmed as follows (see dhThr ${ }^{1}$ in Figure 3). The methyl signal $\left(\delta_{\mathrm{H}} 1.82, \mathrm{~d}, J=7.0 \mathrm{~Hz}, \gamma \mathrm{CH}_{3}\right)$ had clear COSY cross peaks with the olefinic proton at $\delta_{\mathrm{H}} 5.89(\mathrm{q}, J=7.0 \mathrm{~Hz}, \beta H)$, which showed an HMQC cross peak with the carbon at $\delta_{\mathrm{c}} 123.3$ (d). In the $\mathrm{HMBC}$ spectrum, the $\gamma \mathrm{CH}_{3}$ moiety had clear correlations with the double bond carbons $\left(\delta_{\mathrm{c}} 132.8, \mathrm{~s}, \alpha \mathrm{C}\right.$ and $\left.\delta_{\mathrm{c}} 123.3, \mathrm{~d}, \beta \mathrm{C}\right)$, and the $\beta H$ exhibited clear HMBC correlations with the $\alpha \mathrm{C}$ and carbonyl carbon $\left(\delta_{\mathrm{c}} 168.8, \mathrm{~s}, \mathrm{CO}\right)$. These NMR data clearly indicate the presence of a dhThr moiety (Figure 3), and the strong NOE between the $\mathrm{\gamma CH}_{3}$ protons and the $\alpha \mathrm{NH}$ proton demonstrated that the double bond is in the $Z$-configuration. The $\alpha \mathrm{NH}$ proton of dhThr showed a definitive HMBC cross peak with the carbonyl carbon $\left(\delta_{\mathrm{c}} 173.5, \mathrm{~s}, \mathrm{C}-1\right)$ of the fatty acid (FA) and showed NOEs with $\mathrm{H}-2\left(\delta_{\mathrm{H}} 2.64\right.$, m; $2.72, \mathrm{~m})$ of the FA, which exhibited HMBC correlations with $\mathrm{C}-1$, the alcoholic carbon $\left(\delta_{\mathrm{c}} 69.3, \mathrm{~d}, \mathrm{C}-3\right)$ and $\mathrm{C}-4\left(\delta_{\mathrm{c}} 38.2, \mathrm{t}\right)$ of the FA, demonstrating that the 3-hydroxydecanoic acid (the FA) is directly connected to the dhThr moiety via an amide

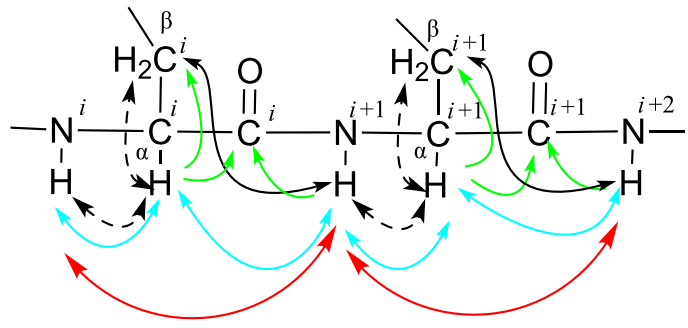

NOE:

$\alpha \mathrm{N}^{i} \mathrm{H} / \alpha \mathrm{C}^{i} \mathrm{H}$ and $\alpha \mathrm{C}^{i} \mathrm{H} / \alpha \mathrm{N}^{i+1} \mathrm{H}$

NOE: $\quad \alpha \mathrm{N}^{i} \mathrm{H} / \alpha \mathrm{N}^{i+1} \mathrm{H}$

NOE: $\quad \beta C^{i} \mathrm{H} / \alpha \mathrm{N}^{i+1} \mathrm{H}$

cosy

$\mathrm{HMBC}$

Figure 4: Key NMR observations used to construct the backbone sequence. 
bond. This structural unit (Figure 3) was further confirmed by the $m / z 254$ ion in the FABMS spectrum of natural cichorinotoxin (Figure 1). We then determined the presence of three dhThr residues in the cichorinotoxin (Figure 6) by analyzing the NMR data; the $\beta \mathrm{CH}$ protons (olefinic protons) of the three dhThr moieties are found at $\delta_{\mathrm{H}} 6.37\left(\mathrm{q}, J=7.0 \mathrm{~Hz}\right.$ ), $\delta_{\mathrm{H}} 6.24$ (q, $J=7.0 \mathrm{~Hz})$ and $\delta_{\mathrm{H}} 5.89(\mathrm{q}, J=7.0 \mathrm{~Hz})$ in the ${ }^{1} \mathrm{H}$ NMR spectrum of the monoacetate (Supporting Information File 1, Figure S7). In the NMR spectra of the monoacetate, $\alpha H\left(\delta_{\mathrm{H}} 4.31\right)$ of $\mathrm{Pro}^{2}$ showed a clear HMBC cross peak with the carbonyl carbon $\left(C \mathrm{O}, \delta_{\mathrm{c}} 168.8, \mathrm{~s}\right)$ of $\mathrm{dhThr}^{1}$, indicating that Pro is the 2 nd amino acid residue, as shown in Figure 3. The five-membered Pro skeleton was confirmed by the COSY and TOCSY spectra, as shown in Figure 3. The FA-dhThr-Pro fragment was further supported by the fragment ion at $m / z 351$ in the FABMS (Figure 1 and Figure 2). As described above, a basic amino acid (positive to the ninhydrin test) is present; thus, the amino group was acetylated under basic conditions to afford the monoacetate of cichorinotoxin (Figure 6). This basic amino acid was determined to be 2,4( $\alpha, \gamma)$-diaminobutanoic acid (Dab-20) by detailed analyses of the NMR data. In the COSY and TOCSY spectra of the acetate, the $\alpha \mathrm{N} H$ proton $\left(\delta_{\mathrm{H}} 8.61\right)$ was correlated with $\alpha \mathrm{CH}\left(\delta_{\mathrm{H}} 3.76\right), \beta \mathrm{CH}_{2}\left(\delta_{\mathrm{H}} 2.33 ; 2.08\right)$ and $\gamma \mathrm{CH}_{2}\left(\delta_{\mathrm{H}} 3.21\right)$. The $\gamma \mathrm{CH}_{2}$ protons had a clear HMBC cross peak with the acetyl carbonyl carbon $\left(\delta_{\mathrm{c}} 170.5, \mathrm{~s}, \mathrm{COCH}_{3}\right)$, as shown in Figure S12B (Supporting Information File 1). The spectrum shown in Figure S12B also indicated that the ester linkage (IR, 1740 $\left.\mathrm{cm}^{-1}\right)$ is between $\beta \mathrm{CH}$ of Thr-18 $\left(\delta_{\mathrm{H}} 5.23, \mathrm{~m}\right)$ and $C \mathrm{O}$ of Val$22\left(\delta_{\mathrm{c}} 170.5, \mathrm{~s}\right)$.

Detailed analyses of the 2D NMR data $\left({ }^{1} \mathrm{H},{ }^{1} \mathrm{H}-\mathrm{COSY}\right.$, TOCSY and NOESY) and ${ }^{1} \mathrm{H},{ }^{13} \mathrm{C}$ correlations (HMQC and HMBC)) of the peptides and proteins [16-18], which are illustrated in Figure 4, allowed us to construct the complete backbone amino acid sequence of cichorinotoxin; the NOESY data are shown in Figures S10A-S10F (Supporting Information File 1), and the HMBC data are shown in Figures S12A-S12C. Figures S10B and S10C highlight the NOE correlations of $\alpha \mathrm{N}^{i} \mathrm{H} / \alpha \mathrm{N}^{i+1} \mathrm{H}$. Figures S10D and S10E mainly depict the NOE correlations of $\alpha \mathrm{N}^{i} \mathrm{H} / \alpha \mathrm{C}^{i} \mathrm{H}$ and $\alpha \mathrm{C}^{i} \mathrm{H} / \alpha \mathrm{N}^{i+1} \mathrm{H}$. Figure S10F mainly highlights the NOEs of $\beta \mathrm{C}^{i} \mathrm{H} / \alpha \mathrm{N}^{i+1} \mathrm{H}$. Distinct NOEs were observed between the $\gamma \mathrm{NH}$ of Dab-20 and $\mathrm{COCH}_{3}$, further verifying that the $\gamma \mathrm{NH}_{2}$ of Dab was acetylated. The HMBC spectrum (Sup- porting Information File 1, Figure S12C) established that $\mathrm{Dab}^{20}$ was acetylated; an HMBC cross peak between $\gamma \mathrm{CH}_{2}$ of $\mathrm{Dab}^{20}$ and $\mathrm{COCH}_{3}$ was observed.

Figure 6 depicts the key NMR data. Tables S1 and S2 (Supporting Information File 1) summarize the ${ }^{1} \mathrm{H}$ and ${ }^{13} \mathrm{C}$ NMR data of the monoacetate. Based on these data, cichorinotoxin contains a lipophilic fatty acid and 22 amino acids, and the peptide part is cyclized through an ester linkage between two of the amino acid residues ( $\mathrm{Thr}^{18}$ and $\mathrm{Val}^{22}$ ). Thus, cichorinotoxin is classified as a cyclic lipodepsipeptide.

To determine the stereochemistry of the amino acids (D or L), we tried to isolate partial fragments by acid hydrolysis. The toxin was dissolved in $12 \mathrm{~N} \mathrm{HCl}$ and reacted for $20 \mathrm{~h}$ at room temperature. The partial hydrolysates were subjected to reversed-phase HPLC $\left(\mathrm{C}_{18}\right)$, which showed that 6 main peptide fragments were produced. These fragments were purified and analyzed by FABMS. The FABMS spectrum of one of the fragments indicated that the segment had the structure shown in Figure 5. This fragment was subjected to acid hydrolysis according to the method described above. Marfey's method revealed the following amino acid composition, including the stereochemistry: Pro $(\mathrm{D} \times 1)$, Ala $(\mathrm{D} \times 4)$ and Val $(\mathrm{D} \times 1)$. None of the other generated peptide fragments were useful for determining stereochemistry. Considering the D or L configurations (Table 1), we could propose the stereochemistry of 12 of the amino acids (including the dhThr moieties), but the stereochemistries of the remaining 10 amino acids remain undetermined (see Figure 6).

\section{NMR data of the tetraacetate}

To further confirm the structure of cichorinotoxin, the tetraacetate was analyzed by NMR $\left(600 \mathrm{MHz}\right.$, acetone- $\left.d_{6}\right)$. The majority of the ${ }^{1} \mathrm{H}$ NMR signals of the tetraacetate (Figure S13A, Supporting Information File 1) were separated, which was not the case in the spectrum of the monoacetate. The TOCSY, COSY and NOESY spectra of the tetraacetate are shown in Figures S13E-S13N (Supporting Information File 1). The NOE data indicated that the amino acid sequence of the tetraacetate is as shown in Figure S14 (Supporting Information File 1). The positions of the acetates were determined mainly from the HMBC and COSY spectra (Figure 7). The $\mathrm{\beta}-\mathrm{CH}_{2}$

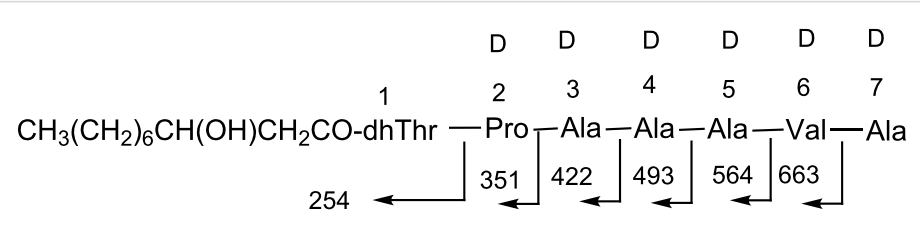

Figure 5: Fragment obtained by acid hydrolysis and each amino acid was exclusively D-configuration (peptide fragment $\mathbf{b}$ ions). 


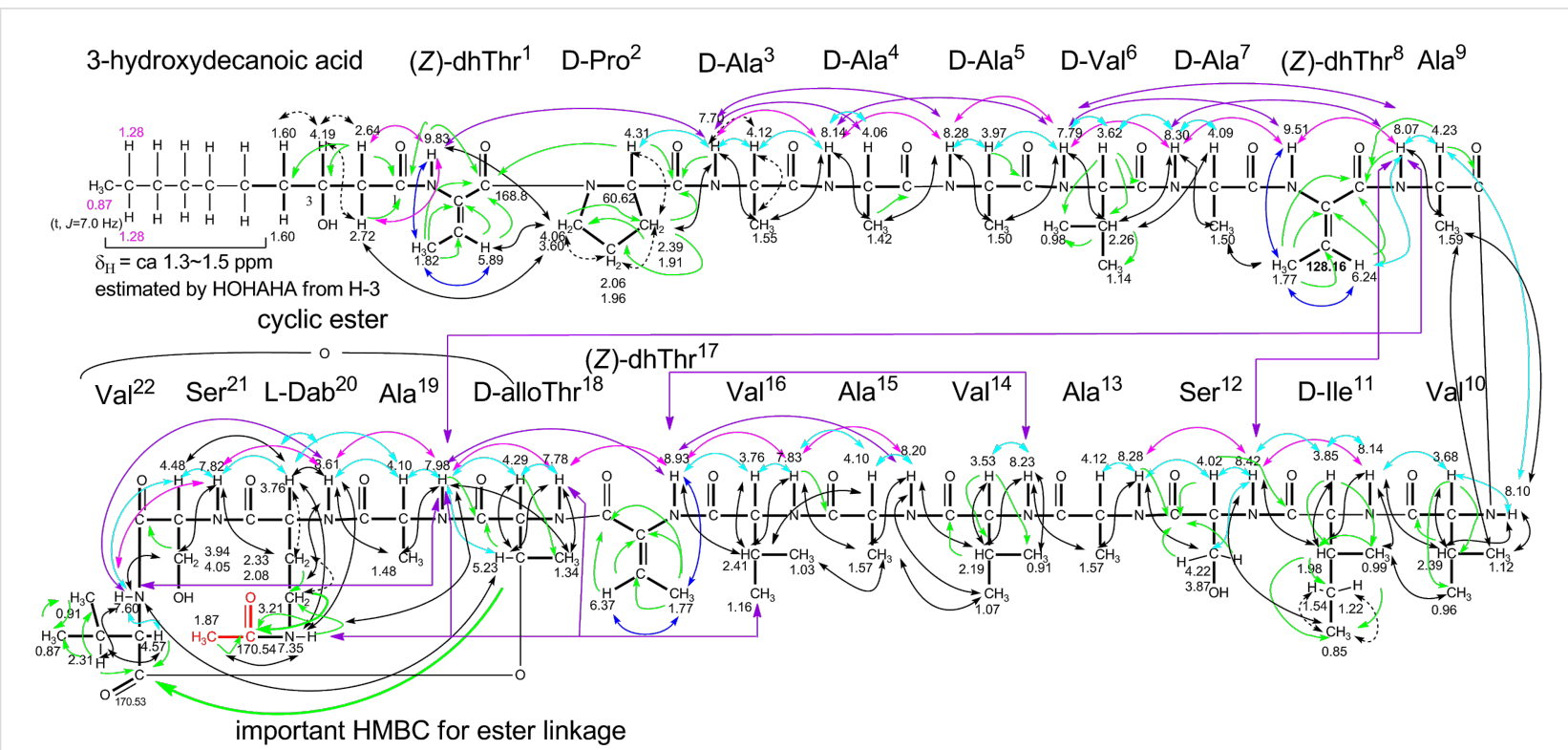

NOE: $\alpha \mathrm{N}^{i} \mathrm{H} / \alpha \mathrm{C}^{i} \mathrm{H}$ and $\curvearrowleft$ NOE: $\alpha \mathrm{N}^{i} \mathrm{H} / \alpha \mathrm{N}^{i+1} \mathrm{H} / \alpha$ long range NOE $\alpha \mathrm{C}^{i} \mathrm{H} / \alpha \mathrm{N}^{i+1} \mathrm{H} \curvearrowleft \mathrm{NOE}: \beta \mathrm{C}^{i} \mathrm{H} / \alpha \mathrm{N}^{i+1} \mathrm{H} \rightleftharpoons \mathrm{COSY}$

NOE observed in the same dhThr molecule

Figure 6: The complete structure of cichorinotoxin monoacetate and the assignments of ${ }^{1} \mathrm{H}$ NMR chemical shifts, which were determined by various 2D NMR techniques.

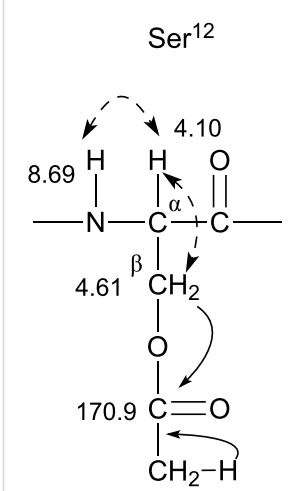

2.08

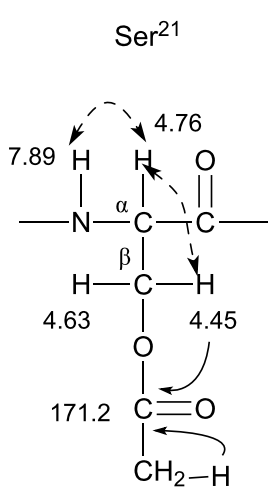

2.08

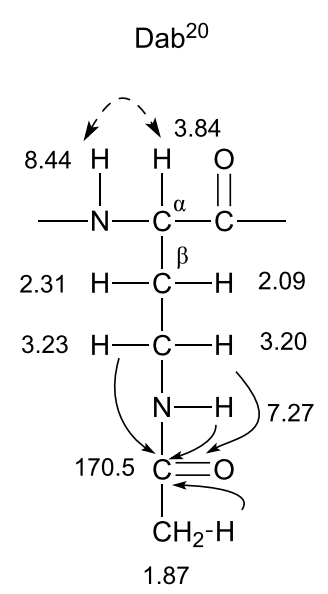

fatty acid residue

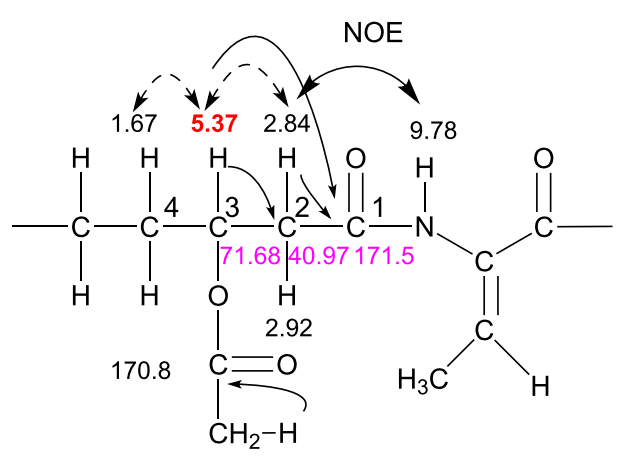

\section{$レ_{\mathrm{COSY}} \rightleftharpoons \mathrm{HMBC} \rightleftharpoons \mathrm{NOE}$}

Figure 7: Determination of the positions of the acetyl groups in the tetraacetate.

protons of $\mathrm{Ser}^{12}, \mathrm{Ser}^{21}$ and $\mathrm{Dab}^{20}$ each had distinct HMBC correlations with one of the acetyl carbonyl carbons, the signals of which were confirmed by clear HMBC cross peaks for the acetyl methyl protons (see Figures S13B-S13D in Supporting Information File 1). Thus, the hydroxy groups of the two Ser residues were acetylated in the tetraacetate, and the amino group of Dab was acetylated in both the monoacetate and the tetraacetate. We found that the hydroxy group at C-3 of the FA residue was acetylated despite the H-3 proton not having a clear HMBC cross peak with the acetyl carbonyl carbon. The $\delta_{\mathrm{H}}$ of 
H-3 in the tetraacetate was shifted downfield by ca. $1.0 \mathrm{ppm}$ (acetylation shift) relative to that in the monoacetate $\left(\delta_{\mathrm{H}} 4.19 \rightarrow \delta_{\mathrm{H}} 5.37\right)$, confirming that the $\mathrm{OH}$ group of the FA was acetylated. Consequently, the complete structure of cichorinotoxin tetraacetate is shown in Figure S14 (Supporting Information File 1), and the fundamental scaffolds, composed of 3-hydroxydecanoic acid and the amino acid sequence backbone, of the mono- and tetraacetates were identical. Tables S3 and S4 (Supporting Information File 1) summarize the assignments of ${ }^{1} \mathrm{H}$ and ${ }^{13} \mathrm{C}$ NMR signal data.

\section{Compounds $\mathbf{A}$ and $\mathbf{B}$ generated by alkaline hydrolysis}

This toxin is composed of a cyclic peptide formed by an ester linkage between the $\mathrm{OH}$ of $\mathrm{Thr}^{18}$ and the $\mathrm{CO}_{2} \mathrm{H}$ of $\mathrm{Val}^{22}$. Figure S15 (Supporting Information File 1) shows the primary structures of cichopeptin A and B [14], syringopeptin 22-A and 22-B [13], corpeptin A and B [19], fuscopeptin [20] and tolaasin I [21,22], which are typical lipodepsipeptides produced by Pseudomonas sp., and they are structural analogues of cichorinotoxin. All of these peptides have a lipophilic fatty acid moiety connected to $\mathrm{dhThr}^{1}$-D-Pro ${ }^{2}$, and the amino acids $\mathrm{dhThr}^{17}$ and allo $\mathrm{Thr}^{18}$ are strictly conserved. Moreover, the conserved alloThr moiety is involved in the cyclic ester linkage. Therefore, the ester bond of natural cichorinotoxin was cleaved by alkaline hydrolysis $(0.02 \mathrm{~N} \mathrm{KOH} / \mathrm{MeOH})$ at room temperature for $5 \mathrm{~h}$ to examine the role of the cyclic structure in the ability to cause varnish spots on lettuce. Two products, $\mathbf{A}$ and $\mathbf{B}$, were generated by the hydrolysis. The FABMS spectrum of compound $\mathbf{A}$ indicated that the MW of $\mathbf{A}$ was identical to that of unreacted cichorinotoxin (Figure S16A, Supporting Information File 1). As shown in Figure S16B, signals for four olefinic protons ( $\beta \mathrm{CH}$ of dhThr) were observed in the ${ }^{1} \mathrm{H}$ NMR spectrum $\left(600 \mathrm{MHz}, \mathrm{DMSO}-d_{6}\right) \delta_{\mathrm{H}} 6.46$ (q, $J=6.6 \mathrm{~Hz}, 1 \mathrm{H}$ for $\left.\mathrm{dhThr}^{17}\right) ; 6.38\left(\mathrm{q}, J=7.0 \mathrm{~Hz}, 1 \mathrm{H}\right.$ for $\left.\mathrm{dhThr}^{8}\right) ; 5.78$ (q,
$J=7.2 \mathrm{~Hz}, 1 \mathrm{H}$ for $\mathrm{dhThr}^{18}$ ) and $5.58(\mathrm{q}, J=6.8 \mathrm{~Hz}, 1 \mathrm{H}$ for $\left.\mathrm{dhThr}^{1}\right)$. This finding indicated that an additional dhThr residue was produced during the hydrolysis. Moreover, the NOE data indicated that the double bond in the newly formed dhThr was in the $E$-geometry (Figures S16C-16E), as shown in Figure 8. The NOE data (Figure 8), which reveal the amino acid sequence, verified that $\mathrm{Thr}^{18}$, which is connected to $\mathrm{CO}_{2} \mathrm{H}$ of $\mathrm{Val}^{22}$ via an ester bond, was changed into dhThr and that the backbone sequence from the fatty acid moiety to $\mathrm{dhThr}^{17}$ was identical to that of parent cichorinotoxin, but the ester bond was cleaved by the alkaline hydrolysis to yield the linear peptide, as shown in Figure 8 and Figure S18 (Supporting Information File 1).

On the other hand, compound $\mathbf{B}$ contained three olefinic protons ( $\beta \mathrm{CH}$ of the dhThr residues) in its structure (Figure S17B), and their signals appeared at $\delta_{\mathrm{H}} 6.37\left(\mathrm{q}, J=7.0 \mathrm{~Hz}, 1 \mathrm{H}\right.$ for $\mathrm{dhThr}^{8}$ ); $5.65\left(\mathrm{q}, J=7.2 \mathrm{~Hz}, 1 \mathrm{H}\right.$ for $\left.\mathrm{dhThr}^{18}\right) ; 5.59(\mathrm{q}, J=7.0 \mathrm{~Hz}, 1 \mathrm{H}$ for $\mathrm{dhThr}^{1}$ ). The chemical shifts of the two olefinic protons of $\mathrm{dhThr}^{8}$ and dhThr ${ }^{1}$ were nearly the same as those of compound A. The NOESY spectrum, shown in Supporting Information File 1, Figure S17F, indicated that the double bonds of dhThr ${ }^{8}$ and $\mathrm{dhThr}^{1}$ were in the $Z$-configuration, which is identical to unreacted cichorinotoxin, but the $E$-geometry was found for the double bond of dhThr ${ }^{18}$, which is identical to that of compound A. The amino acid sequence of compound $\mathbf{B}$ was determined mainly from its NOESY spectrum (Supporting Information File 1, Figures S17C, D and E). The fatty acid moiety was retained, and the sequence from $\mathrm{dhThr}^{1}$ to $\mathrm{Ala}^{16}$ was the same as that of unreacted cichorinotoxin. As shown in Figure 9, the 17th residue was Thr-like amino acid, which was different from that (dhThr) in the parent cichorinotoxin and in compound $\mathbf{A}$. The subsequent amino acids in the sequence (18th to $22 \mathrm{nd}$ ) were identical to those in compound A. However, it is notable that the residue in the 17th position was not in fact genuine $\mathrm{Thr}$

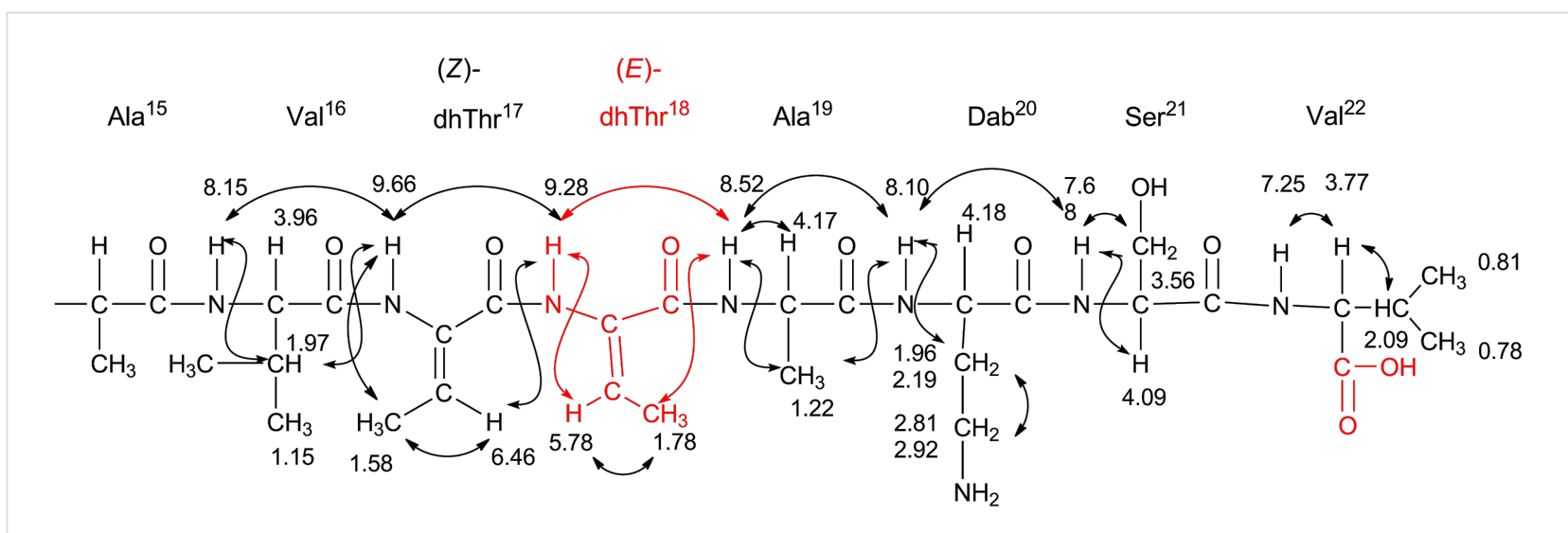

Figure 8: Partial structure of compound $\mathbf{A}$ as deduced from its NOE data; key NOEs are represented by double-headed arrows. The $\delta_{H}$ (ppm) are given, and these signals were measured in DMSO- $d_{6}(600 \mathrm{MHz})$. The double bond of $\mathrm{dhThr}^{18}$ was in the $E$-configuration. 


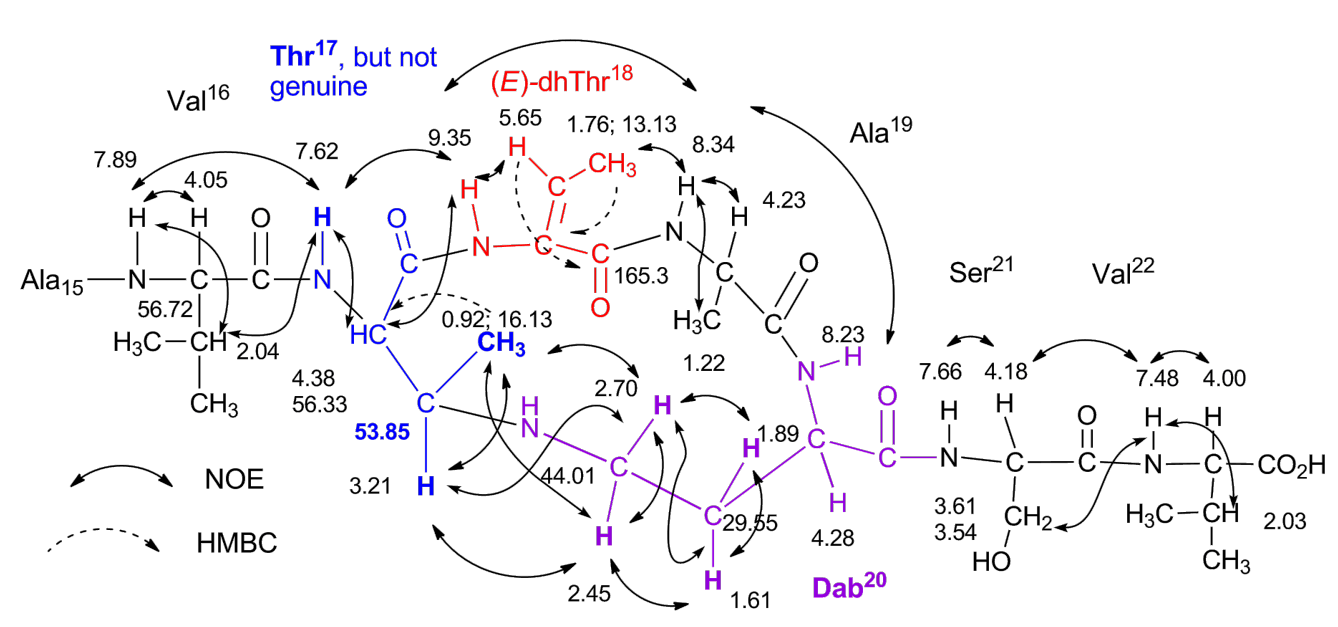

Figure 9: Partial structure of compound $\mathbf{B}\left(\mathrm{Val}^{16}\right.$ to $\mathrm{Val}^{22}$ residues). The chemical shifts $\left(\delta_{\mathrm{H}}\right.$ and $\left.\delta_{\mathrm{C}}(\mathrm{ppm})\right)$ are shown, and these values were obtained in DMSO- $d_{6}(600 \mathrm{MHz}$ NMR instrument).

because the chemical shift of $\beta C \mathrm{H}$ was $\delta_{\mathrm{C}}$ (ppm) 53.85, which is significantly upfield compared with the resonance of this carbon in genuine Thr (approximately $67 \mathrm{ppm} \beta C \mathrm{H}-\mathrm{O}$ function). Furthermore, distinct NOEs were observed between the $\gamma \mathrm{CH}$ protons of $\mathrm{Dab}^{20}$ and the $\beta \mathrm{CH}$ protons of the 17th amino acid (Thr-like) and between the $\gamma \mathrm{CH}$ protons of $\mathrm{Dab}^{20}$ and the $\gamma \mathrm{CH}_{3}$ protons of the 17th Thr-like amino acid. These data unambiguously indicated that the Thr-like residue was linked with Dab through the $\gamma$-nitrogen atom of $\mathrm{Dab}^{20}$, as shown in Figure 9.

Consequently, the overall structures of compounds $\mathbf{A}$ and $\mathbf{B}$ are depicted in Figure S18 (Supporting Information File 1). Figure 10 shows the reaction mechanisms for generating compounds $\mathbf{A}$ and $\mathbf{B}$ from cichorinotoxin by treatment with dilute $\mathrm{KOH}$. The proton at $\alpha$-position of D-allo $\mathrm{Thr}^{18}$ was first eliminated by the base $\left(\mathrm{OH}^{-}\right.$ion $)$, followed by the release of $\mathrm{Val}^{22}$ $\mathrm{COO}^{-}$ion and the production of dhThr. This process follows an E2-type elimination mechanism (see a Newman projection), thus leading to compound $\mathbf{A}$, which has an $E$-double bond for dhThr instead of a Z-double bond. Compound $\mathbf{A}$ was further converted into compound $\mathbf{B}$ by nucleophilic attack of the free amino group of $\mathrm{Dab}^{20}$ on the C-3 of dhThr ${ }^{17}$.

\section{Necrotic lesion on lettuce by cichorinotoxin derivatives (mono- and tetraacetates and compounds $\mathbf{A}$ and $\mathbf{B}$ )}

Figure S19A (Supporting Information File 1) shows the bioassay method. Figure S19B indicates that the necrotic lesions caused by the monoacetate (3) were somewhat less severe, but the compound was still active; the tetraacetate (4) showed almost no activity. For the monoacetate (3), the hydrophilic $\mathrm{NH}_{2}$ of $\mathrm{Dab}^{20}$, which is one of the residues in the macrocycle of the peptide, is acetylated. The tetraacetate (4), in which the fatty acid, two serine residues $\left(\mathrm{Ser}^{12}\right.$ and $\mathrm{Ser}^{21}$ ) and $\mathrm{Dab}^{20}$ are all acylated, had no activity. $\mathrm{Ser}^{12}$, which is present in the linear portion of the peptide, is not conserved in the toxins listed in Supporting Information File 1, Figure S15; thus, it is likely that the hydrophilic $\mathrm{Ser}^{21}$, embedded in the macrocycle of the peptide, is crucial for the necrosis activity. The peptides in the macrocycle, listed in Supporting Information File 1, Figure S15, consist of 5 or 8 amino acids, and of these, at least two of the hydrophilic amino acids are conserved; this could be the DabSer or the Dab-Dab sequence for example. The conversion of the two hydrophilic amino acids into hydrophobic residues by acylation may have caused the complete loss of activity seen with the tetraacetate (4). Acyclic compound A (a linear lipopeptide) produced by alkaline treatment had no activity, supporting that a macrocyclic peptide would be essential for biological activity. The sequence $Z$-dhThr ${ }^{17}$-D-alloThr ${ }^{18}$ of cichorinotoxin was converted to $Z$-dhThr ${ }^{17}-E$-dhThr ${ }^{18}$ by alkaline hydrolysis. This additional structural modification may have further decreased the activity. Compound $\mathbf{B}$ has a macrocycle composed of 4-amino acids, but it exhibited no necrotic activity. As seen in the structures of all the toxins depicted in Figure S15 (Supporting Information File 1), the macrocycles are in terminal positions; thus, having the macrocycle at the termini may be required for the toxic activity. At the present stage, the crucial structural units for the toxic activity cannot be specified and are still uncertain. Further studies are required.

\section{Conclusion}

In summary, we succeeded in proposing the overall structure of cichorinotoxin, 3-hydroxydecanoyl-(Z)-dhThr ${ }^{1}$-D-Pro ${ }^{2}$-D-Ala ${ }^{3}$ D-Ala - D-Ala ${ }^{5}-\mathrm{D}-\mathrm{Val}^{6}{ }^{6} \mathrm{D}-\mathrm{Ala}^{7}-(Z)-\mathrm{dhThr}^{8}-\mathrm{Ala}^{9}-\mathrm{Val}^{10}{ }^{10} \mathrm{D}-\mathrm{Ile}^{11}$ $\mathrm{Ser}^{12}-\mathrm{Ala}^{13}$-Val $^{14}-\mathrm{Ala}^{15}{ }_{-} \mathrm{Val}^{16}{ }^{16}(Z)-\mathrm{dhThr}^{17}$-D-allo $\mathrm{Thr}^{18}{ }^{18} \mathrm{Ala}^{19}{ }^{19}$ $\mathrm{L}-\mathrm{Dab}^{20}-\mathrm{Ser}^{21}-\mathrm{Val}^{22}$, in which an ester linkage is formed be- 


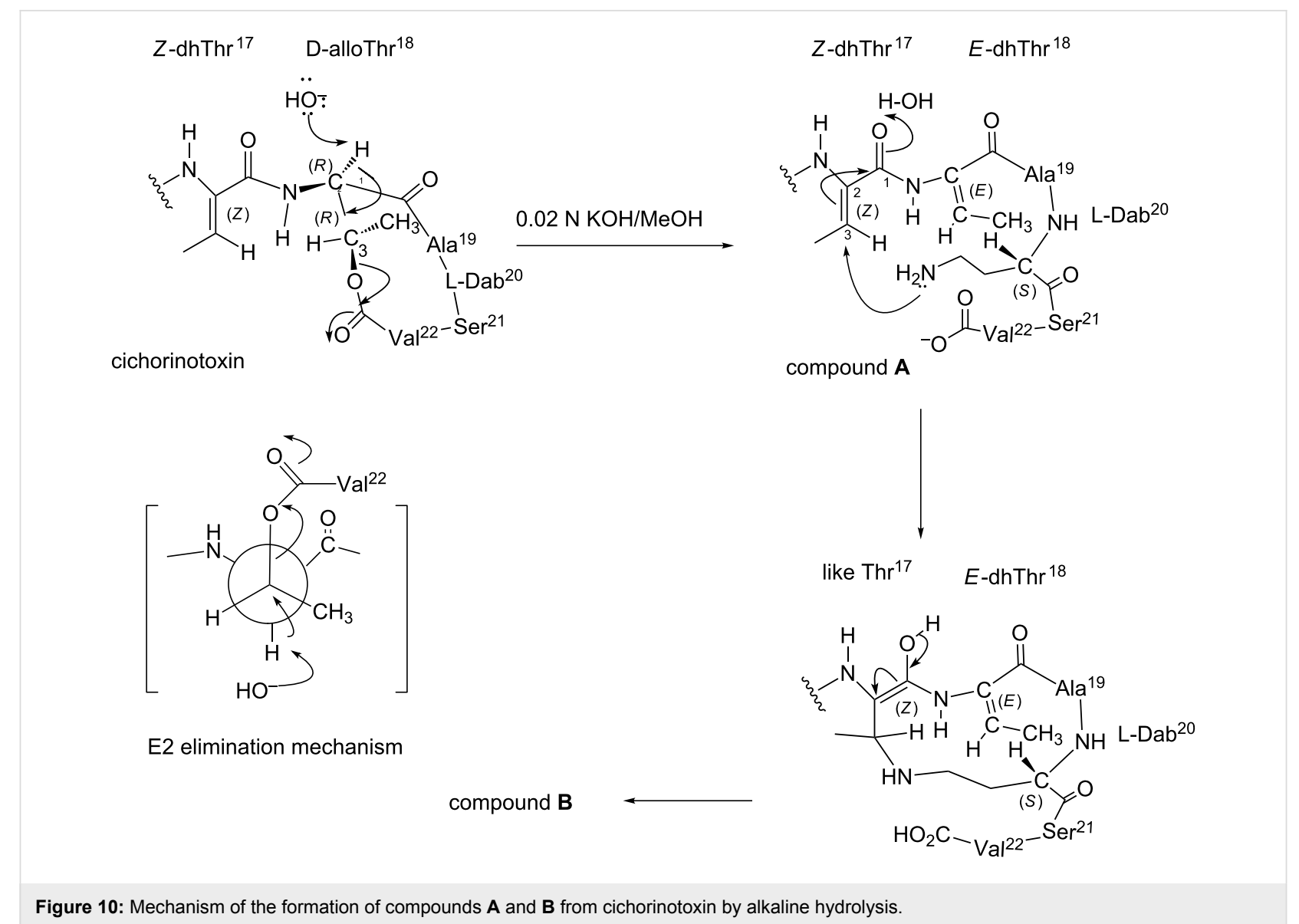

Figure 10: Mechanism of the formation of compounds A and B from cichorinotoxin by alkaline hydrolysis.

tween D-allo $\mathrm{Thr}^{18}$ and $\mathrm{Val}^{22}$. The configurations (D or L) of all 22 amino acids could not be determined in the present study. Authentic D-[1- $\left.{ }^{13} \mathrm{C}\right]$ - and L-[1- $\left.{ }^{13} \mathrm{C}\right]-$ Val were separately fed into cultures of $P$. cichorii $\mathrm{YM} 8705$, and the cichorinotoxin thus obtained was analyzed by ${ }^{13} \mathrm{C}$ NMR spectroscopy. Five Val residues (four D-Val and one L-Val) are included in cichorinotoxin (Figure 6 and Table 1). All the five ${ }^{13} \mathrm{C}$ signals of $\mathrm{CO}$ - of $\mathrm{Val}$ residues appeared with almost the same signal intensities in each of the ${ }^{13} \mathrm{C}$ NMR spectra, which were obtained by the feedings of L- and D-Val (Figure S20B and S20C, Supporting Information File 1). This finding definitively demonstrated that an epimerase (racemase) is involved in the biosynthetic gene cluster. Differences in the ${ }^{13} \mathrm{C}$ signal intensities were a little in the feeding experiments using L- or D-[1- $\left.{ }^{13} \mathrm{C}\right]-\mathrm{Ala}$ (see Figure S20D and S20E, Supporting Information File 1). These results indicated that an epimerase is involved in the biosynthetic gene cluster of this strain. Thus, we failed to assign the $\mathrm{D}$ or $\mathrm{L}$ configurations for all the amino acids by the feeding experiments. However, we succeeded in proposing the complete stereochemistry of the molecule by careful analysis of the biosynthetic gene cluster (nonribosomal peptide synthetases, NRPS). These results will be reported in due course. The present studies gave some information of which structural units are required for the toxic activity, but are not sufficient. Further investigations are necessary to address the structure-activity relationship.

\section{Experimental \\ General analytical methods}

NMR spectra were recorded in acetone- $d_{6}$ on a Bruker DMX 600 spectrometer; the chemical shifts $(\delta)$ are given in ppm relative to the residual solvent peaks $\left(\delta_{\mathrm{H}} 2.04\right.$ and $\left.\delta_{\mathrm{C}} 29.80\right)$ as the internal references for the ${ }^{1} \mathrm{H}$ and ${ }^{13} \mathrm{C}$ NMR spectra, respectively. In the case of DMSO- $d_{6}$ solutions, the chemical shifts are given in ppm relative to the solvent peaks $\left(\delta_{\mathrm{H}} 2.49\right.$ and $\left.\delta_{\mathrm{C}} 39.50\right)$. The coupling constants, $J$, are given in Hz. FABMS spectra were obtained on a JEOL SX 100 spectrometer using $m$-nitrobenzyl alcohol (NBA). A Shimadzu LC-10A HPLC apparatus and a Shimadzu SPD-10AVP detector were used to determine the $\mathrm{D}$ or $\mathrm{L}$ configuration of each amino acid.

\section{Bioassay method}

The necrotic lesions were detected by the method given in Figure S19A (Supporting Information File 1). The lesions were usually detected after standing for 1 day. In the cases of the mono- and tetraacetates and compounds $\mathbf{A}$ and $\mathbf{B}$, the necrotic 
activities significantly decreased; thus, the samples were allowed to stand for 3 days to estimate the activities, as shown in Supporting Information File 1, Figure S19B.

\section{Isolation of cichorinotoxin}

Pseudomonas cichorii isolate YM8705 has been deposited in NARO Genebank as MAFF730229 (NARO: National Agricultural and Food Research Organization).

P. cichorii YM8705 was cultured in YPD medium (polypeptone (10 g, Nippon Shinyaku Ltd), dry yeast extract (5 g, Oxoid Ltd.), $\mathrm{NaCl}(3 \mathrm{~g})$ and mannitol (5 g, Wako Ltd.) in $1000 \mathrm{~mL}$ of $\mathrm{H}_{2} \mathrm{O}$ ). Precultured seeds were grown at $28{ }^{\circ} \mathrm{C}$ for $24 \mathrm{~h}$ in $100 \mathrm{~mL}$ of YPD medium using a $500 \mathrm{~mL}$ Sakaguchi flask with reciprocal shaking. Next, $10 \mathrm{~mL}$ of the precultured seed culture was inoculated into $1000 \mathrm{~mL}$ of the YPD medium and cultured at $28{ }^{\circ} \mathrm{C}$ for $72 \mathrm{~h}$. The cells obtained from $6 \mathrm{~L}$ of culture were collected by centrifugation and lyophilized. The dried cells were soaked in approximately $1.0 \mathrm{~L}$ of $\mathrm{MeOH}$ and stirred at room temperature for $2 \mathrm{~h}$. The cells were then removed by filtration. The methanolic fraction, which contained the crude cichorinotoxin, was developed with a mixed solvent of $\left(\mathrm{CH}_{3}\right)_{2} \mathrm{CO} / \mathrm{MeOH}(2: 1)$ on a $\mathrm{SiO}_{2}$ TLC. The toxin was visualized as a yellowish white spot by spraying either a BTB reagent or deionized water. Crude cichorinotoxin was obtained by $\mathrm{SiO}_{2}$ column chromatography eluting with the above solvent. Pure cichorinotoxin was obtained by reversed-phase HPLC (column: Shiseido CAPCEL PAK $\mathrm{C}_{18}$ UG120; mobile phase: $\mathrm{MeOH} /$ $1 \%$ aqueous $\mathrm{NH}_{3}=87: 13$, detected at $254 \mathrm{~nm}$ ) in a yield of approximately $122 \mathrm{mg}$. Melting point: $181-184^{\circ} \mathrm{C}$.

\section{Preparation of the monoacetate and the tetraacetate} This toxin $(6.0 \mathrm{mg})$ was dissolved in $5 \mathrm{~mL}$ of a mixture $(1: 1)$ of $\mathrm{CH}_{3} \mathrm{CN}$ and $0.01 \mathrm{M}$ carbonate buffer solution ( $\mathrm{pH} 9.7$ ), and then $1.5 \mathrm{~mL}$ of $\mathrm{Ac}_{2} \mathrm{O}$ was added. The reaction was carried out at room temperature for $6 \mathrm{~h}$. Almost all of the toxin had been consumed by $\mathrm{SiO}_{2}$ TLC analysis. Complete purification was achieved by reversed-phase HPLC (MeOH/ $1 \%$ aq $\left.\mathrm{NH}_{3}=83: 17\right)$, yielding $5.4 \mathrm{mg}$ of the monoacetate. Cichorinotoxin $(8.0 \mathrm{mg}$ ) was dissolved in Py $(3.0 \mathrm{mg})$, and $1.5 \mathrm{~mL}$ of $\mathrm{Ac}_{2} \mathrm{O}$ was added. The reaction was continued for $1 \mathrm{~h}$ at ambient temperature, and the crude material was purified by the same HPLC conditions as described for the monoacetate to afford $6.8 \mathrm{mg}$ of the tetraacetate.

\section{Determination of the amino acid composition and of the $D$ and $L$ configurations}

To $1.0 \mathrm{mg}$ of cichorinotoxin was added $1.0 \mathrm{~mL}$ of $6 \mathrm{~N} \mathrm{HCl}$, and the mixture was frozen at $-30{ }^{\circ} \mathrm{C}$ and degassed under a high vacuum pump. The glass vessel was sealed and heated at $110^{\circ} \mathrm{C}$ for $5 \mathrm{~h}, 10 \mathrm{~h}$ and $22 \mathrm{~h}$ to obtain the hydrolysates, each of which were concentrated to dryness. The residues were evaluated using an amino acid analyzer. Marfey's method was employed to determine the stereochemistry of each of the amino acids. The dried hydrolysates obtained by heating for $10 \mathrm{~h}$ were dissolved in $140 \mu \mathrm{L}$ of $\mathrm{H}_{2} \mathrm{O}$. To $25 \mu \mathrm{L}$ of the solution were added 1\% Marfey's reagent ((1-fluoro-2,4-dinitro-5-fluorophenyl)-L-alaninamide, $1.8 \mu \mathrm{M})$ dissolved in acetone and $10 \mu \mathrm{L}$ of $1 \mathrm{M} \mathrm{NaHCO}_{3}(10 \mu \mathrm{M})$. The solution was heated at $35^{\circ} \mathrm{C}$ for $1 \mathrm{~h}$, then $2 \mathrm{~N}$ aq $\mathrm{HCl}$ was added to quench the reaction, and then it was concentrated to dryness. The residues were dissolved in DMSO and subjected to reversed-phase HPLC $\left(\mathrm{C}_{18}\right)$ using a mobile phase composed of $13 \% \mathrm{CH}_{3} \mathrm{CN} / 87 \% 50 \mathrm{mM}$ triethylamine phosphate. Amino acid compositions of natural cichorinotoxin (not Marfey's derivatives) were analyzed by Hitachi Keisoku Service Ltd (Tokyo).

\section{Partially hydrolyzed peptide fragments}

Seven milliliters of $12 \mathrm{~N} \mathrm{HCl}$ was added to $15 \mathrm{mg}$ of cichorinotoxin, and the reaction was allowed to stand at room temperature for $20 \mathrm{~h}$. The hydrolysates were subjected to reversedphase HPLC (the same ODS column) using $\mathrm{MeOH} / \mathrm{H}_{2} \mathrm{O}$ (58:42) with $0.3 \% \mathrm{NH}_{3}$ and afforded 6 major peaks. After purification, only one peak remained in the HPLC chromatogram, and this compound was analyzed by FABMS. To clarify the stereochemistry of the amino acids present, Marfey's method was employed.

\section{Hydrolysis of cichorinotoxin in a basic medium}

The purified toxin $(26 \mathrm{mg})$ was dissolved in $0.02 \mathrm{~N} \mathrm{KOH} /$ $\mathrm{MeOH}$ and allowed to stand at ambient temperature for $5 \mathrm{~h}$. This reaction mixture was neutralized with $2 \mathrm{~N}$ aq $\mathrm{HCl}$ and then lyophilized. The residue was subjected to reversed-phase HPLC (C18) eluting with $\mathrm{MeOH} / 1 \%$ aq $\mathrm{NH}_{3}$ (71:29), and the eluate was monitored at $254 \mathrm{~nm}$. New peaks from compounds $\mathbf{A}$ (earlier elution) and $\mathbf{B}$ (later elution) were observed in addition to the peak of cichorinotoxin. The isolated yields were as follows: $2.5 \mathrm{mg}$ for compound $\mathbf{A}$; $6.3 \mathrm{mg}$ for compound $\mathbf{B}$; and $6.1 \mathrm{mg}$ of recovered cichorinotoxin.

\section{Feeding experiments of $D$ - and L-[1-13 C]Val and -Ala}

P. cichorii YM8705 was grown in the culture medium composed of the following compositions: mannitol $(10 \mathrm{~g})$, $\mathrm{Na}_{2} \mathrm{HPO}_{4} \cdot 12 \mathrm{H}_{2} \mathrm{O}(3 \mathrm{~g}), \mathrm{KH}_{2} \mathrm{PO}_{4}(0.5 \mathrm{~g}), \mathrm{NaCl}(3 \mathrm{~g})$, $\left(\mathrm{NH}_{4}\right)_{2} \mathrm{SO}_{4}(1 \mathrm{~g}), \mathrm{MgSO}_{4} \cdot 7 \mathrm{H}_{2} \mathrm{O}(25 \mathrm{mg}), \mathrm{CaCl}_{2} \cdot 2 \mathrm{H}_{2} \mathrm{O}(23 \mathrm{mg})$ and dry yeast extract $(0.1 \mathrm{~g})$ dissolved in $1000 \mathrm{~mL}$ of $\mathrm{H}_{2} \mathrm{O}$. To the $500 \mathrm{~mL}$ Sakaguchi flask containing $100 \mathrm{~mL}$ medium, 25-40 mg of the labelled Val and Ala was aseptically added and then grown at $28{ }^{\circ} \mathrm{C}$ for $120 \mathrm{~h}$. The labelled cichorinotoxins were isolated by the same HPLC conditions as described above. 


\section{Supporting Information}

\section{Supporting Information File 1}

Analytical data $\left({ }^{1} \mathrm{H},{ }^{13} \mathrm{C}\right.$ NMR, IR and MS), photographs of bioassay methods.

[https://www.beilstein-journals.org/bjoc/content/ supplementary/1860-5397-15-27-S1.pdf]

\section{Acknowledgements}

Dr. Shinobu Fujimura in this department (Niigata University) assisted in a preliminary work to clarify the amino acid composition. We also thank Prof. Fumio Sugawara, Tokyo University of Science, for valuable comments on the structural determination. One of the authors (T. Shirakawa) appreciates the financial support from the Science and Technology Agency (Japan), which allowed him to structurally characterize this toxin in this department of Niigata University. Special thanks are given to the late Prof. T. Uchiyama, who made a great contribution to this investigation in an earlier research stage.

\section{ORCID ${ }^{\circledR}$ iDs}

Tsutomu Hoshino - https://orcid.org/0000-0002-8484-2752

\section{References}

1. Grogan, R. G.; Misaghi, I. J.; Kimble, K. A.; Greathead, A. S.; Ririe, D.; Bardin, R. Phytopathology 1977, 67, 957-960. doi:10.1094/phyto-67-957

2. Kiba, A.; Lee, K. Y.; Ohnishi, K.; Park, P.; Nakayashiki, H.; Tosa, Y.; Mayama, S.; Hikichi, Y. Physiol. Mol. Plant Pathol. 2009, 74, 45-54. doi:10.1016/j.pmpp.2009.08.006

3. Kiba, A.; Sangawa, Y.; Ohnishi, K.; Yao, N.; Park, P.; Nakayashiki, H.; Tosa, Y.; Mayama, S.; Hikichi, Y. Mol. Plant-Microbe Interact. 2006, 19, 112-122. doi:10.1094/mpmi-19-0112

4. Pauwelyn, E.; Vanhouteghem, K.; Cottyn, B.; De Vos, P.; Maes, M.; Bleyaert, P.; Höfte, M. J. Phytopathol. 2011, 159, 298-305. doi:10.1111/j.1439-0434.2010.01764.x

5. Shirakawa, T.; Hoshino, T.; Uchiyama, T.; Ozaki, K. In Abstr. Ann. Meeting Phytopathol. Soc. Jpn., Ann. Meeting Phytopathol. Soc. Jpn.; 1992; pp 599 ff.

6. Shirakawa, T. Kongetsu no Nougyou, published by The Chemical Daily Co., Ltd., 1995, 5, 67-70 (Japanese).

7. Shirakawa, T.; Ozaki, K. In Abstr. Ann. Meeting Phytopathol. Soc. Jpn., Ann. Meeting Phytopathol. Soc. Jpn.; 1994.

8. Takasugi, M.; Okinaka, S.; Katsui, N.; Masamune, T.; Shirata, A.; Ohuchi, M. J. Chem. Soc., Chem. Commun. 1985, 621-622. doi:10.1039/c39850000621

9. Isogai, A.; Fukuchi, N.; Yamashita, S.; Suyama, K.; Suzuki, A. Tetrahedron Lett. 1990, 31, 695-698. doi:10.1016/s0040-4039(00)94605-7

10. Fukuchi, N.; Isogai, A.; Yamashita, S.; Suyama, K.; Takemoto, J. Y.; Suzuki, A. Tetrahedron Lett. 1990, 31, 1589-1592. doi:10.1016/0040-4039(90)80024-g
11. Segre, A.; Bachmann, R. C.; Ballio, A.; Bossa, F.; Grgurina, I.; lacobellis, N. S.; Marino, G.; Pucci, P.; Simmaco, M.; Takemoto, J. Y. FEBS Lett. 1989, 255, 27-31. doi:10.1016/0014-5793(89)81054-3

12. Ballio, A.; Bossa, F.; Collina, A.; Gallo, M.; lacobellis, N. S.; Paci, M.; Pucci, P.; Scaloni, A.; Segre, A.; Simmaco, M. FEBS Lett. 1990, 269, 377-380. doi:10.1016/0014-5793(90)81197-v

13. Ballio, A.; Barra, D.; Bossa, F.; Collina, A.; Grgurina, I.; Marino, G.; Moneti, G.; Paci, M.; Pucci, P.; Segre, A.; Simmaco, M. FEBS Lett. 1991, 291, 109-112. doi:10.1016/0014-5793(91)81115-o

14. Huang, C.-J.; Pauwelyn, E.; Ongena, M.; Debois, D.; Leclère, V.; Jacques, P.; Bleyaert, P.; Höfte, M. Mol. Plant-Microbe Interact. 2015, 28, 1009-1022. doi:10.1094/mpmi-03-15-0061-r

15. Marfey, P. Carlsberg Res. Commun. 1984, 49, 591-596. doi:10.1007/bf02908688

16. Wüthrich, K. NMR of Proteins and Nucleic Acids; John Wiley \& Sons, Inc., 1986.

17. Wüthrich, K. NMR in biological research: peptides and proteins; North-Holland, American Elsevier, Inc., 1976.

18. Gronen, A. M.; Clore, G. M. Chapter 9. In Spectroscopic Methods for Determining Protein Structure in Solution; Havel, H. A., Ed.; VCH Publishers, Inc., 1996.

19. Emanuele, M. C.; Scaloni, A.; Lavermicocca, P.; Jacobellis, N. S.; Camoni, L.; Di Giorgio, D.; Pucci, P.; Paci, M.; Segre, A.; Ballio, A. FEBS Lett. 1998, 433, 317-320. doi:10.1016/s0014-5793(98)00933-8

20. Ballio, A.; Bossa, F.; Camoni, L.; Di Giorgio, D.; Flamand, M.-C.; Maraite, H.; Nitti, G.; Pucci, P.; Scaloni, A. FEBS Lett. 1996, 381, 213-216. doi:10.1016/0014-5793(96)00043-9

21. Nutkins, J. C.; Mortishire-Smith, R. J.; Packman, L. C.; Brodey, C. L.; Rainey, P. B.; Johnstone, K.; Williams, D. H. J. Am. Chem. Soc. 1991, 113, 2621-2627. doi:10.1021/ja00007a040

22. Bassarello, C.; Lazzaroni, S.; Bifulco, G.; Lo Cantore, P.; lacobellis, N. S.; Riccio, R.; Gomez-Paloma, L.; Evidente, A. J. Nat. Prod. 2004, 67, 811-816. doi:10.1021/np0303557

\section{License and Terms}

This is an Open Access article under the terms of the Creative Commons Attribution License (http://creativecommons.org/licenses/by/4.0). Please note that the reuse, redistribution and reproduction in particular requires that the authors and source are credited.

The license is subject to the Beilstein Journal of Organic Chemistry terms and conditions: (https://www.beilstein-journals.org/bjoc)

The definitive version of this article is the electronic one which can be found at: doi: $10.3762 /$ bjoc. 15.27 